\title{
Stories Notebook about the Fundamental Concepts in Family Medicine: Uncertainty. The Fable of the Zebra and the Horse
}

Jose Luis Turabian *

Health Center Santa Maria de Benquerencia Toledo, Spain

*Corresponding author: Jose Luis Turabian, Health Center Santa Maria de Benquerencia Toledo, Spain, Tel: 34925154508; Email: jturabianf@hotmail.com

Received date: March 15, 2017; Accepted date: March 25, 2017; Published date: March 31, 2017

Copyright: ( 2017 Turabian JL. This is an open access article distributed under the terms of the Creative Commons Attribution License, which permits unrestricted use, distribution, and reproduction in any medium, provided the original author and source are credited.

Keywords: Family medicine; General medicine; Clinical practice; Clinical trials

\section{Introduction}

In this section of Stories Notebook about the Fundamental Concepts in Family Medicine, you will learn the fundamental concepts of General Medicine/Family Medicine through stories or fables.

Conceptual systematization in the specialty of Family Medicine/ General Medicine has not matched with practice. However, it is not until that the conceptual heritage of Family Medicine, is ordered, systematized and fully clarified when it can begin the real practical work [1].

Therefore, it is necessary to achieve more meaningful representations of the fundamental concepts of Family Medicine, and facilitate the transfer of these to clinical practice. But, these concepts can be difficult to understand and explain, even for experienced physicians in the specialty. Thus, we propose the following concepts of Family Medicine/General Medicine, which we think are the main:

- Comprehensiveness and integrality

- Continuity

- Context and contextualization

- Uncertainty

- Complexity

- Community

- Patient-centered interview

- Biopsicosocial model

- Actors and resources/strengths of the patients

- Medicalization and technology

- Family

- Symptoms

- Diagnosis and treatment

- Concept of health and disease; and

- Variability

Evidence-Based Medicine, clinical trials and quantitative studies are necessary, indispensable for medical science, yes, but why not the stories, the tales and the cases? So, we will be presented these concepts by fables [2-5].

The fable is an adult education method that can serve to intuitively understand abstract concepts by linking them to specific situations, for facilitating their assimilation. Animals, plants, minerals and other things will be "patients" seen in consultation by the family doctor.

They will be fictional stories presented as real. They will be beings or objects that are given the opportunity to think, feel and speak. In the fable it can be distinguished two parts: one is the story itself; and the other moral. Each story seeks to make emerge, of clear form, the moral, the end of the fable, as sobering consequence of what happened in the episode [6]. The moral will be a fundamental concept of Family Medicine/General Medicine.

\section{Short Communication}

Once upon a time Mr. Horse had headache and consulted his family doctor.

"It hurts the whole head. It is a pain of mild or moderate intensity that appeared two days ago. I notice it more in the middle of the head; sometimes it seems that it is like a heartbeat, my neck hurts ... "said the Lord Horse.

The next patient was Mrs. Zebra. She also had headache.

"It hurts the whole head. It's a sharp pain that appeared 2 hours ago. My eye is red and it is crying. ", said Mrs. Zebra.

The doctor values the possibilities of diagnostic in these patients: "horses or zebras. Horses are the common diseases; I must propose the most logical solution and maintain a diagnostic tree open to other possibilities. Zebras are the rare diseases, but it should not be considered impossible."

When a patient comes to the office with a new problem in family medicine, the doctor must face a certain amount of uncertainty about their assessment and optimal treatment [7-11].

"Migraine, meningitis, tumors, hemorrhage, neuralgia, ENT disorders, headache associated with general processes (such as hypertension), psychogenic headache..." the family doctor was mentally reviewing the differential diagnosis.

And he continues: "Do I lack data on a clinical case or a problem? Do I need to document myself more about this problem? I need less knowledge of problem and more about context? Can I see the difference between the background and figure, and so see its shape? Can I sense the position in space of the patient, family and community in their relationship or in relation to us?"

"How should I do the tests: in parallel or sequentially? And according to tests in parallel or sequential, that do I can expect on the sensitivity and predictive value? According I did use one way or another to do the test, what consequences can I expect regarding diseases that could escape to me diagnostic or could do over diagnosis? What is the relationship between prevalence and predictive value of a test? What impact has this relationship in the diagnosis of 'rare cases'?". The doctor asks himself. 
"I have to remember that the sensitivity and specificity are somewhat relative, not absolute; they change according to the conditions or situations where a patient is."

"What is the most serious condition that this could be?" The doctor continues asking himself. "After relevant research on patient history, appropriate clinical examination and appropriate laboratory tests or other investigations, I can see that there is no indication of a serious illness, so I can be reasonably sure that the patient will be except (Figure 1)

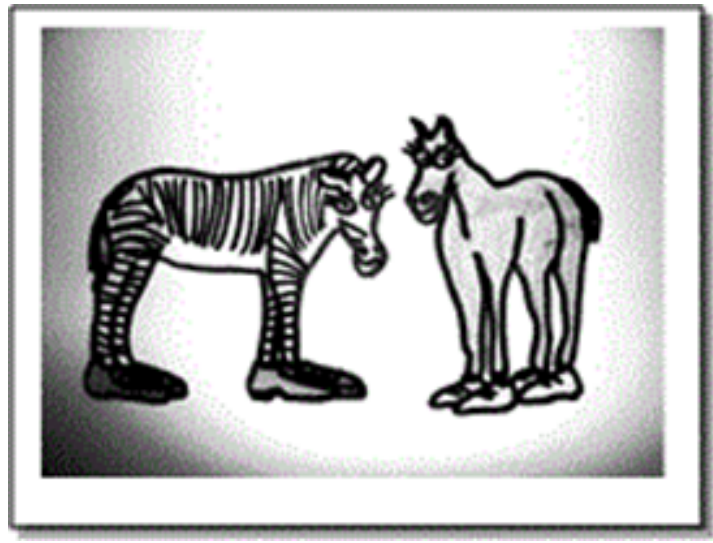

Figure 1: The fable of the zebra and the horse.

"I know that uncertainty is often represented in terms of probability or in terms of normative reasoning, and the evidence-based medicine is the most successful effort to apply statistics to clinical decision theory $[12,13]$. But the initial criterion for assessing the success of an approach to the uncertainty will be that the intervention be helpful."

"Moreover, we must work tolerating that great uncertainty in decisions. Tolerance for uncertainty means the ability to receive much conflicting information without forcing the situation, and maintain an internal locus of evaluation [14-18]."

\section{Summary and Conclusion}

Family doctors, unlike specialists, are working in an environment where there is a high prevalence of symptoms of discomfort but a low prevalence of established disease. This means that the family doctor have to use very different diagnostic strategies to those used in the hospital setting. The family doctor, often must diagnose what not be, more than what be, and has to make treatment decisions before reaching to final diagnoses [18]. The family doctor work can be helped by care managers to coordinate patient care and supporting in the use of other community resources.

The family doctor should think first and foremost about the most common problems, but he also has to think about those rare but serious diseases. The family physician specializes in "the frequent". Or rather, he or she has that "exclude the worst possibility and then assisting Nature in its healing processes [19-22]."

The simplest explanation is the most appropriate (Ockham's knife William of Ockham, Scottish philosopher, S XIV: "You must not multiply entities without reason, we must always go to the simplest hypothesis"). Between two explanations, choose the clearest one; between two forms, the most elemental; between two expressions, the shortest. Look for simplicity [1-22].

\section{References}

1. Howie JGR (1974) Further observations on diagnosis and management of general practice respiratory illness using simulated patient consultations. BMJ 2: 540-543.

2. Farkas C (2013) Potentially harmful side-effects: Medically unexplained symptoms, somatization, and the Insufficient Illness narrative for viewers of Mystery Diagnosis. J Med Humanit 34: 315.

3. Tufton N, Freudenthal R, Barnard M (2012) A rare cause of a leg ulcer in a patient with diabetes. British Journal of Diabetes Vascular Disease 12: 98-100.

4. Leeflang MMG, Rutjes AWS, Reitsma JB, Hooft L, Bossuyt PMM (2013) Variation of test's sensivity and specificity with disease prevalence. CMAJ 185: E537-E544.

5. Turabian JL, Perez Franco B (2006) The process by which family doctors manage uncertainty: Not everything is zebras or horses. Aten Primaria 38: 165-167.

6. Smith CS, Paauw DS (2000) When you hear hoof beats: Four principles for separating zebras from horses. J Am Board Fam Pract 13: 424-429.

7. Fernández JLT, Pérez Franco B (2005) A way to make clinical pragmatism operative: Sistematization of the actuation of competent physicians. Med Clin (Barc) 124: 476

8. Gill CJ, Sabin L, Schmid CH (2005) Why clinicians are natural bayesians. BMJ 330: 1080-1083.

9. Arnold PC (2007) A dangerous truth. Med J Aust 186: 215-216.

10. Wimmers PF, Splinter TAW, Hancock GR, Schmidt HG (2007) Clinical Competence: General ability or case-specific? Advances in Health Sciences Education 12: 299-314.

11. Eva K W, Link CL, Lutfey KE, McKinlay JB (2010) Swapping Horses Midstream: Factors related to Physicians' Changing their minds about a diagnosis. Acad Med 85: 1112-1117.

12. Heath I (1999) William Pickles Lecture 1999: 'Uncertain clarity': contradiction, meaning, and hope. Br J Gen Pract 49: 651-657.

13. Turabián JL, Pérez-Franco B. (2015) Cuentos de fantasmas para aprender medicina de familia. Haciendo conscientes los métodos para gestionar la incertidumbre en medicina de familia. Editorial Académica Española.

14. Turabian Jl, Perez Franco B (2014) Album of models for qualitative tools in the Family Medicine decision making. Other maps to describe a country. Semergen 40.

15. Turabian JL, Perez Franco B (2006) Variablility is an Indicator of Good Clinical Management in Family Medicine. Aten Primaria 37: 160-161.

16. Turabian Jl, Perez Franco B (2007) Framework of Competences of Family Doctors: Clinics or People? Aten Primaria 39: 41-43.

17. Turabian JL (2009) Specific tools to manage complex consultations in general practice. BMJ 338: b1187.

18. Turabián JL (2003) Una medicina a escala humana. JANO LXV(1489): 10.

19. Rogers C (1961) On becoming a person. Boston: Houghton Mifflin Company, USA.

20. Mandell BF (2016) There may be zebras running with the horses. CCJM 83: 697-702.

21. Simpkin AL, Schwartzstein RM (2016) Tolerating Uncertainty - The Next Medical Revolution? N Engl J Med 375: 1713-1715.

22. Ciccone MM, Aquilino A, Cortese F, Scicchitano P, Sassara M, et al. (2010) Feasibility and effectiveness of a disease and care management model in the primary health care system for patients with heart failure and diabetes (Project Leonardo). Vasc Health Risk Manag 6: 297-305. 